\title{
Clinical application of array-based comparative genomic hybridization by two-stage screening for 536 patients with mental retardation and multiple congenital anomalies
}

\author{
Shin Hayashi ${ }^{1,2}$, Issei Imoto ${ }^{1,3}$, Yoshinori Aizu ${ }^{4}$, Nobuhiko Okamoto $^{5}$, Seiji Mizuno ${ }^{6}$, Kenji Kurosawa ${ }^{7}$, \\ Nana Okamoto ${ }^{1,8}$, Shozo Honda ${ }^{1}$, Satoshi Araki ${ }^{9}$, Shuki Mizutani ${ }^{9}$, Hironao Numabe ${ }^{10}$, Shinji Saitoh ${ }^{11}$, \\ Tomoki Kosho ${ }^{12}$, Yoshimitsu Fukushima ${ }^{12}$, Hiroshi Mitsubuchi ${ }^{13}$, Fumio Endo ${ }^{13}$, Yasutsugu Chinen ${ }^{14}$, \\ Rika Kosaki $^{15}$, Torayuki Okuyama ${ }^{15}$, Hirotaka Ohki ${ }^{16}$, Hiroshi Yoshihashi ${ }^{17}$, Masae Ono ${ }^{18}$, Fumio Takada ${ }^{19}$, \\ Hiroaki Ono $^{20}$, Mariko Yagi ${ }^{21}$, Hiroshi Matsumoto ${ }^{22}$, Yoshio Makita ${ }^{23}$, Akira Hata ${ }^{24}$ and Johji Inazawa ${ }^{1,25}$
}

Recent advances in the analysis of patients with congenital abnormalities using array-based comparative genome hybridization (aCGH) have uncovered two types of genomic copy-number variants (CNVs); pathogenic CNVs (pCNVs) relevant to congenital disorders and benign CNVs observed also in healthy populations, complicating the screening of disease-associated alterations by aCGH. To apply the aCGH technique to the diagnosis as well as investigation of multiple congenital anomalies and mental retardation (MCA/MR), we constructed a consortium with 23 medical institutes and hospitals in Japan, and recruited 536 patients with clinically uncharacterized MCA/MR, whose karyotypes were normal according to conventional cytogenetics, for two-stage screening using two types of bacterial artificial chromosome-based microarray. The first screening using a targeted array detected pCNV in 54 of 536 cases (10.1\%), whereas the second screening of the 349 cases negative in the first screening using a genomewide high-density array at intervals of approximately $0.7 \mathrm{Mb}$ detected pCNVs in 48 cases (13.8\%), including pCNVs relevant to recently established microdeletion or microduplication syndromes, CNVs containing pathogenic genes and recurrent CNVs containing the same region among different patients. The results show the efficient application of aCGH in the clinical setting. Journal of Human Genetics (2011) 56, 110-124; doi:10.1038/jhg.2010.129; published online 28 October 2010

Keywords: array-CGH; congenital anomaly; mental retardation; screening

\section{INTRODUCTION}

Mental retardation (MR) or developmental delay is estimated to affect $2-3 \%$ of the population. ${ }^{1}$ However, in a significant proportion of cases, the etiology remains uncertain. Hunter ${ }^{2}$ reviewed 411 clinical cases of MR and reported that a specific genetic/syndrome diagnosis was carried out in $19.9 \%$ of them. Patients with MR often have congenital anomalies, and more than three minor anomalies can be useful in the diagnosis of syndromic MR., Although chromosomal aberrations are well-known causes of MR, their frequency determined by conventional karyotyping has been reported to range from 7.9 to $36 \%$ in patients with $\mathrm{MR}^{4-8}$ Although the diagnostic yield depends on the population of each study or clinical conditions, such studies

${ }^{1}$ Department of Molecular Cytogenetics, Medical Research Institute and School of Biomedical Science, Tokyo Medical and Dental University, Tokyo, Japan; ${ }^{2}$ Hard Tissue Genome Research Center, Tokyo Medical and Dental University, Tokyo, Japan; ${ }^{3}$ Department of Human Genetics and Public Health Graduate School of Medical Science, The University of Tokushima, Tokushima, Japan; ${ }^{4}$ Division of Advanced Technology and Development, BML, Saitama, Japan; ${ }^{5}$ Department of Medical Genetics, Osaka Medical Center and Research Institute for Maternal and Child Health, Osaka, Japan; ${ }^{6}$ Department of Pediatrics, Central Hospital, Aichi Human Service Center, Kasugai, Japan; ${ }^{7}$ Division of Medical Genetics, Kanagawa Children's Medical Center, Yokohama, Japan; ${ }^{8}$ Department of Maxillofacial Orthognathics, Graduate School, Tokyo Medical and Dental University, Tokyo, Japan; ${ }^{9}$ Department of Pediatrics and Developmental Biology, Tokyo Medical and Dental University Graduate School, Tokyo, Japan; ${ }^{10}$ Department of Medical Genetics, Kyoto University Hospital, Kyoto, Japan; ${ }^{11}$ Department of Pediatrics, Hokkaido University Graduate School of Medicine, Sapporo, Japan; ${ }^{12}$ Department of Medical Genetics, Shinshu University School of Medicine, Matsumoto, Japan; ${ }^{13}$ Department of Pediatrics, Kumamoto University Graduate School of Medical Science, Kumamoto, Japan; ${ }^{14}$ Department of Pediatrics, University of the Ryukyu School of Medicine, Okinawa, Japan; ${ }^{15}$ Department of Clinical Genetics and Molecular Medicine, National Center for Child Health and Development, Tokyo, Japan; ${ }^{16}$ The Division of Cardiology, Tokyo Metropolitan Children's Medical Center, Tokyo, Japan; ${ }^{17}$ The Division of Medical Genetics, Tokyo Metropolitan Children's Medical Center, Tokyo, Japan; ${ }^{18}$ Department of Pediatrics, Tokyo Teishin Hospital, Tokyo, Japan; ${ }^{19}$ Department of Medical Genetics, Kitasato University Graduate School of Medical Sciences, Sagamihara, Japan; ${ }^{20}$ Department of Pediatrics, Hiroshima Prefectural Hospital, Hiroshima, Japan; ${ }^{21}$ Department of Pediatrics, Kobe University Graduate School of Medicine, Kobe, Japan; ${ }^{22}$ Department of Pediatrics, National Defense Medical College, Saitama, Japan; ${ }^{23}$ Education Center, Asahikawa Medical College, Asahikawa, Japan; ${ }^{24}$ Department of Public Health, Chiba University Graduate School of Medicine, Chiba, Japan and ${ }^{25}$ Global Center of Excellence (GCOE) Program for 'International Research Center for Molecular Science in Tooth and Bone Diseases', Tokyo Medical and Dental University, Tokyo, Japan

Correspondence: Professor J Inazawa, Department of Molecular Cytogenetics, Medical Research Institute, Tokyo Medical and Dental University, 1-5-45 Yushima, Bunkyo-ku, Tokyo 113-8510, Japan.

E-mail: johinaz.cgen@mri.tmd.ac.jp

Received 20 August 2010; revised 25 September 2010; accepted 30 September 2010; published online 28 October 2010 
suggest that at least three quarters of patients with MR are undiagnosed by clinical dysmorphic features and karyotyping.

In the past two decades, a number of rapidly developed cytogenetic and molecular approaches have been applied to the screening or diagnosis of various congenital disorders including MR, congenital anomalies, recurrent abortion and cancer pathogenesis. Among them, array-based comparative genome hybridization (aCGH) is used to detect copy-number changes rapidly in a genome-wide manner and with high resolution. The target and resolution of aCGH depend on the type and/or design of mounted probes, and many types of microarray have been used for the screening of patients with MR and other congenital disorders: bacterial artificial chromosome (BAC)-based arrays covering whole genomes, ${ }^{9,10} \mathrm{BAC}$ arrays covering chromosome $\mathrm{X},{ }^{11,12}$ a BAC array covering all subtelomeric regions, ${ }^{13}$ oligonucleotide arrays covering whole genomes, ${ }^{14,15}$ an oligonucleotide array for clinical diagnosis ${ }^{16}$ and a single nucleotide polymorphism array covering the whole genome. ${ }^{17}$ Because genome-wide aCGH has led to an appreciation of widespread copy-number variants (CNVs) not only in affected patients but also in healthy populations, ${ }^{18-20}$ clinical cytogenetists need to discriminate between CNVs likely to be pathogenic (pathogenic CNVs, pCNVs) and CNVs less likely to be relevant to a patient's clinical phenotypes (benign CNVs, bCNVs). ${ }^{21}$ The detection of more CNVs along with higher-resolution microarrays needs more chances to assess detected CNVs, resulting in more confusion in a clinical setting.

We have applied aCGH to the diagnosis and investigation of patients with multiple congenital anomalies and MR (MCA/MR) of unknown etiology. We constructed a consortium with 23 medical institutes and hospitals in Japan, and recruited 536 clinically uncharacterized patients with a normal karyotype in conventional cytogenetic tests. Two-stage screening of copy-number changes was performed using two types of BAC-based microarray. The first screening was performed by a targeted array and the second screening was performed by an array covering the whole genome. In this study, we diagnosed well-known genomic disorders effectively in the first screening, assessed the pathogenicity of detected CNVs to investigate an etiology in the second screening and discussed the clinical significance of aCGH in the screening of congenital disorders.

\section{MATERIALS AND METHODS}

\section{Subjects}

We constructed a consortium of 23 medical institutes and hospitals in Japan, and recruited 536 Japanese patients with MCA/MR of unknown etiology from July
2005 to January 2010. All the patients were physically examined by an expert in medical genetics or a dysmorphologist. All showed a normal karyotype by conventional approximately 400-550 bands-level G-banding karyotyping. Genomic DNA and metaphase chromosomes were prepared from peripheral blood lymphocytes using standard methods. Genomic DNA from a lymphoblastoid cell line of one healthy man and one healthy woman were used as a normal control for male and female cases, respectively. All samples were obtained with prior written informed consent from the parents and approval by the local ethics committee and all the institutions involved in this project. For subjects in whom CNV was detected in the first or second screening, we tried to analyze their parents as many as possible using aCGH or fluorescence in situ hybridization (FISH).

\section{Array-CGH analysis}

Among our recently constructed in-house BAC-based arrays, ${ }^{22}$ we used two arrays for this two-stage survey. In the first screening we applied a targeting array, 'MCG Genome Disorder Array' (GDA). Initially GDA version 2, which contains 550 BACs corresponding to subtelomeric regions of all chromosomes except $13 p, 14 p, 15 p, 21 p$ and $22 p$ and causative regions of about 30 diseases already reported, was applied for 396 cases and then GDA version 3, which contains 660 BACs corresponding to those of GDA version 2 and pericentromeric regions of all chromosomes, was applied for 140 cases. This means that a CNV detected by GDA is certainly relevant to the patient's phenotypes. Subsequently in the second screening we applied 'MCG Whole Genome Array-4500' (WGA-4500) that covers all 24 human chromosomes with 4523 BACs at intervals of approximately $0.7 \mathrm{Mb}$ to analyze subjects in whom no $\mathrm{CNV}$ was detected in the first screening. WGA- 4500 contains no BACs spotted on GDA. If necessary, we also used 'MCG X-tiling array' (X-array) containing 1001 BAC/PACs throughout $\mathrm{X}$ chromosome other than pseudoautosomal regions. ${ }^{12}$ The array-CGH analysis was performed as previously described. ${ }^{12,23}$

For several subjects we applied an oligonucleotide array (Agilent Human Genome CGH Microarray 244K; Agilent Technologies, Santa Clara, CA, USA) to confirm the boundaries of CNV identified by our in-house BAC arrays. DNA labeling, hybridization and washing of the array were performed according to the directions provided by the manufacturer. The hybridized arrays were scanned using an Agilent scanner (G2565BA), and the CGH Analytics program version 3.4.40 (Agilent Technologies) was used to analyze copy-number alterations after data extraction, filtering and normalization by Feature Extraction software (Agilent Technologies).

\section{Fluorescence in situ hybridization}

Fluorescence in situ hybridization was performed as described elsewhere ${ }^{23}$ using BACs located around the region of interest as probes.

\section{RESULTS}

CNVs detected in the first screening

In the first screening, of 536 cases subjected to our GDA analysis, $54(10.1 \%)$ were determined to have CNV (Figure 1; Tables 1 and 2).

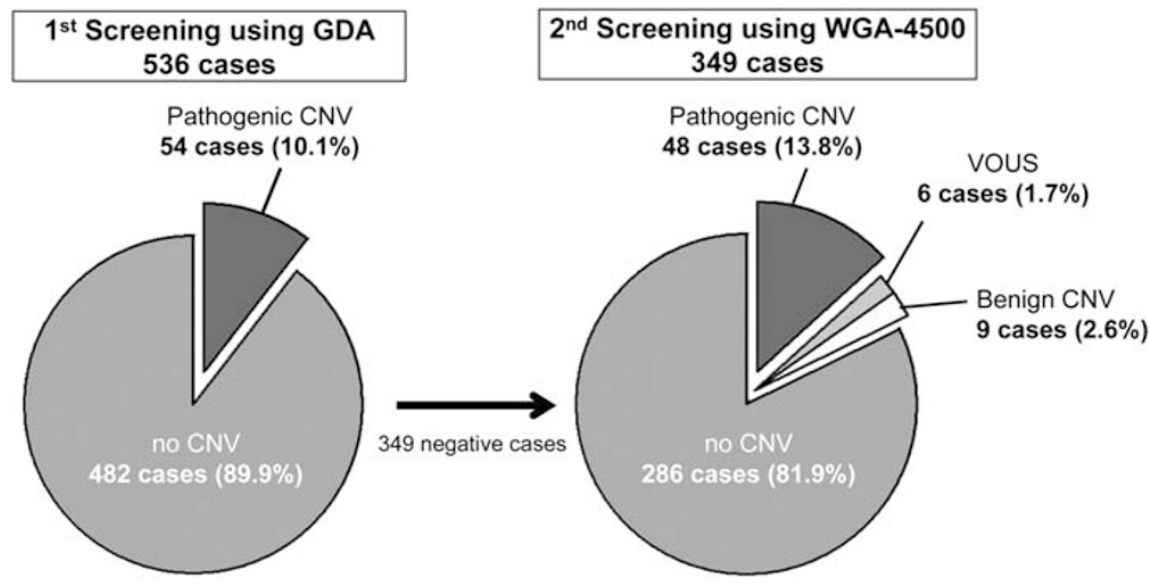

Figure 1 Percentages of each screening in the current study. 
Table 1 A total of 40 cases with CNV at subtelomeric region(s) among 54 positive cases in the first screening

\begin{tabular}{|c|c|c|c|c|c|}
\hline \multirow[b]{2}{*}{ Gender } & \multicolumn{2}{|c|}{ Position where CNV detected } & \multirow[b]{2}{*}{ Corresponding disorder ${ }^{a}$} & \multirow[b]{2}{*}{ OMIM or citation } & \multirow[b]{2}{*}{ Parental analysis ${ }^{\mathrm{b}}$} \\
\hline & Loss & Gain & & & \\
\hline M & $1 \mathrm{p} 36.33$ & & Chromosome 1 p36 deletion syndrome & \#607872 & \\
\hline M & 1 p36.33p36.32 & & Chromosome 1 p36 deletion syndrome & \#607872 & \\
\hline M & $1 p 36.33 p 36.32$ & & Chromosome 1 p36 deletion syndrome & \#607872 & \\
\hline M & $1 p 36.33 p 36.32$ & & Chromosome $1 \mathrm{p} 36$ deletion syndrome & \#607872 & \\
\hline M & $1 q 44$ & & Chromosome $1 q 43-q 44$ deletion syndrome & \#612337 & \\
\hline $\mathrm{F}$ & $2 q 37.3$ & & 2q37 monosomyc & Shrimpton et al. ${ }^{24}$ & \\
\hline $\mathrm{F}$ & $2 q 37.3$ & & $2 q 37$ monosomyc & Shrimpton et al. ${ }^{24}$ & \\
\hline M & $3 q 29$ & & Chromosome 3q29 deletion syndrome & \#609425 & \\
\hline $\mathrm{F}$ & $5 p 15.33 p 15.32$ & & Cri-du-chat syndrome & $\# 123450$ & \\
\hline M & $5 q 35.2 q 35.3$ & & Chromosome $5 q$ subtelomeric deletion syndrome & Rauch et al. ${ }^{25}$ & \\
\hline $\mathrm{F}$ & $6 p 25.3$ & & Chromosome 6pter-p24 deletion syndrome & \#612582 & \\
\hline M & $7 q 36.3$ & & $7 q 36$ deletion syndrome ${ }^{d}$ & Horn et al. ${ }^{26}$ & \\
\hline $\mathrm{F}$ & $7 q 36.3$ & & $7 q 36$ deletion syndrome ${ }^{d}$ & Horn et al. ${ }^{26}$ & \\
\hline M & $9 p 24.3 p 24.2$ & & Chromosome 9p deletion syndrome & \#158170 & \\
\hline $\mathrm{F}$ & $9 q 34.3$ & & Kleefstra syndrome & \#610253 & \\
\hline $\mathrm{F}$ & $10 q 26.3$ & & Chromosome 10q26 deletion syndrome & \#609625 & \\
\hline $\mathrm{F}$ & $16 \mathrm{p} 13.3$ & & Chromosome $16 \mathrm{p} 13.3$ deletion syndrome & \#610543 & \\
\hline $\mathrm{F}$ & $22 q 13.31$ & & Chromosome $22 q 13$ deletion syndrome & \#606232 & \\
\hline M & $22 q 13.31 q 13.33$ & & Chromosome $22 q 13$ deletion syndrome & \#606232 & \\
\hline M & & $15 q 26.3$ & $15 q$ overgrowth syndrome ${ }^{c}$ & Tatton-Brown et al. ${ }^{27}$ & \\
\hline $\mathrm{F}$ & & $15 q 26.3$ & $15 q$ overgrowth syndrome $e^{c}$ & Tatton-Brown et al. ${ }^{27}$ & \\
\hline M & & $21 q 22.13 q 22.3$ & Down's syndrome (partial trisomy 21) & \#190685 & \\
\hline M & & Xp22.33 & A few cases have been reported; e.g. V5-130 in Lu et al. ${ }^{28}$ & & \\
\hline M & & Xq28 & Chromosome Xq28 duplication syndrome & \#300815 & \\
\hline \multirow[t]{2}{*}{$\mathrm{F}$} & $1 q 44$ & & Chromosome 1q43-q44 deletion syndrome & \#612337 & \\
\hline & & $8 p 23.2 p 23.3$ & & & \\
\hline \multirow[t]{2}{*}{ M } & $3 p 26.3$ & & $3 p$ deletion syndrome ${ }^{d}$ & Fernandez et al..29 & \\
\hline & & $12 p 13.33 p 11.22$ & & & \\
\hline \multirow[t]{2}{*}{$\mathrm{F}$} & $3 p 26.3$ & & $3 p$ deletion syndrome $e^{d}$ & Fernandez et al..29 & \\
\hline & & $16 \mathrm{p} 13.3$ & Chromosome 16p13.3 duplication syndrome & \#613458 & \\
\hline \multirow[t]{2}{*}{$\mathrm{F}$} & $4 q 35.2$ & & $4 q-$ syndrome $^{d}$ & Jones et al. ${ }^{30}$ & \\
\hline & & $7 q 36.3$ & & & \\
\hline \multirow[t]{2}{*}{ M } & $5 p 15.33$ & & Cri-du-chat syndrome & \#123450 & \\
\hline & & $20 p 13$ & & & \\
\hline \multirow[t]{2}{*}{ M } & $5 p 15.33 p 15.32$ & & Cri-du-chat syndrome & $\# 123450$ & \\
\hline & & $2 p 25.3$ & & & \\
\hline \multirow[t]{2}{*}{$\mathrm{F}$} & $6 q 27$ & & $6 q$ terminal deletion syndrome $e^{d}$ & Striano et al. ${ }^{31}$ & \\
\hline & & $11 q 25$ & & & \\
\hline \multirow[t]{2}{*}{$\mathrm{F}$} & $6 q 27$ & & $6 q$ terminal deletion syndrome ${ }^{d}$ & Striano et al. ${ }^{31}$ & \\
\hline & & $8 q 24.3$ & & & \\
\hline \multirow[t]{2}{*}{ M } & $7 q 36.3$ & & $7 q 36$ deletion syndrome ${ }^{d}$ & Horn et al. ${ }^{26}$ & $d n$ \\
\hline & & $1 q 44$ & & & \\
\hline \multirow[t]{2}{*}{ M } & $9 p 24.3 p 24.2$ & & Chromosome 9p deletion syndrome & \#158170 & \\
\hline & & $7 q 36.3$ & & & \\
\hline \multirow[t]{2}{*}{$\mathrm{F}$} & $10 p 15.3 p 15.2$ & & Chromosome $10 p$ terminal deletion ${ }^{d}$ & Lindstrand et al. ${ }^{32}$ & pat \\
\hline & & $7 p 22.3 p 22.2$ & & & \\
\hline \multirow[t]{2}{*}{ M } & $10 p 15.3$ & & Chromosome $10 p$ terminal deletion ${ }^{d}$ & Lindstrand et al. ${ }^{32}$ & \\
\hline & & $2 p 25.3$ & & & \\
\hline M & $10 q 26.3$ & & Chromosome 10q26 deletion syndrome & \#609625 & \\
\hline & & $2 q 37.3$ & Distal trisomy $2 q^{d}$ & Elbracht et al. ${ }^{33}$ & \\
\hline M & $18 q 23$ & & Chromosome $18 \mathrm{q}$ deletion syndrome & \#601808 & \\
\hline & & $7 q 36.3$ & & & \\
\hline $\mathrm{F}$ & $22 q 13.31 q 13.33$ & & Chromosome $22 q 13.3$ deletion syndrome & \#606232 & pat \\
\hline & & $17 q 25.3$ & One case was reported & Lukusa et al..$^{34}$ & \\
\hline M & Xp22.33/Yp11.32 & & Contiguous gene-deletion syndrome on $\mathrm{Xp} 22.3^{\mathrm{d}}$ & Fukami et al. ${ }^{35}$ & \\
\hline & & Xq27.3q28 & Chromosome Xq28 duplication syndrome & \#300815 & \\
\hline
\end{tabular}

Abbreviations: F, female; CNV, copy-number variant; M, male; OMIM, Online Mendelian Inheritance in Man; $d n$, de novo CNV observed in neither of the parents.

aThe name of disorder is based on entry names of OMIM, expect for entry names in DECIPHER and description in each cited article.

bpat, father had a balanced translocation involved in corresponding subtelomeric regions.

'Entry names in DECIPHER.

${ }^{d}$ Description in each cited article. 
All the CNVs detected in the first screening were confirmed by FISH. Among the positive cases, in 24 cases one CNV was detected. All the CNVs corresponded to well-established syndromes or already described disorders (Table 1). In 16 cases two CNVs, one deletion and one duplication, were detected at two subtelomeric regions, indicating that one of parents might be a carrier with reciprocal translocation involved in corresponding subtelomeric regions, and at least either of the two CNVs corresponded to the disorders. We also performed parental analysis by FISH for three cases whose parental samples were available, and confirmed that in two cases the subtelomeric aberrations were inherited from paternal balanced translocation and in one case the subtelomeric aberrations were de novo (Table 1). In the other 14 cases, CNVs $(25.9 \%)$ were detected in regions corresponding to known disorders (Table 2).

CNVs detected in the second screening and assessment of the CNVs Cases were subject to the second screening in the order of subjects detected no $\mathrm{CNV}$ in the first screening, and until now we have analyzed 349 of 482 negative cases in the first screening. In advance, we excluded highly frequent CNVs observed in healthy individuals and/or in multiple patients showing disparate phenotypes from the present results based on an internal database, which contained all results of aCGH analysis we have performed using WGA-4500, or other available online databases; for example, Database of Genomic Variant (http://projects.tcag.ca/variation/). As a result, we detected 66 CNVs in 63 cases (Figure 1; Table 3). Among them, three patients (cases 36, 42 and 44) showed two CNVs. All the CNVs detected in the second screening were confirmed by other cytogenetic methods including FISH and/or X-array. For 60 cases, we performed FISH for confirmation and to determine the size of each CNV. For five cases, cases 13, 36, 48, 57 and 63, with CNVs on the X chromosome, we used the X-array instead of FISH. For cases 4, 6, 16-19 and 34, we also used Agilent Human Genome CGH Microarray $244 \mathrm{~K}$ to determine the refined sizes of CNVs. The maximum and minimum sizes of each CNV determined by these analyses are described in Table 3 .

\section{Well-documented pCNVs emerged in the second screening}

$C N V$ s identified for recently established syndromes. We assessed the pathogenicity of the detected CNVs in several aspects (Figure 2). ${ }^{21,37,38}$ First, in nine cases, we identified well-documented pCNVs, which are responsible for syndromes recently established. A heterozygous deletion at 1q41-q42.11 in case 2 was identical to patients in the first report of 1q41q42 microdeletion syndrome. ${ }^{39}$ Likewise a CNV in case 3 was identical to chromosome 1q43-q44 deletion syndrome (OMIM: \#612337), ${ }^{40} \mathrm{a} \mathrm{CNV}$ in case 4 was identical to 2 q23.1 microdeletion syndrome, ${ }^{41} \mathrm{a} \mathrm{CNV}$ in case 5 was identical to $14 \mathrm{q} 12$ microdeletion syndrome ${ }^{42}$ and a CNV in case 6 was identical to chromosome 15q26-qter deletion syndrome (Drayer's syndrome) (OMIM: \#612626). ${ }^{43}$ Cases 7, 8 and 9 involved CNVs of different sizes at 16p12.1-p11.2, the region responsible for 16p11.2-p12.2 microdeletion syndrome. ${ }^{44,45}$ Although an interstitial deletion at $1 \mathrm{p} 36.23$ p36.22 observed in case 1 partially overlapped with a causative region of chromosome 1p36 deletion syndrome (OMIM: \#607872), the region deleted was identical to a proximal interstitial $1 \mathrm{p} 36$ deletion that was recently reported. ${ }^{46}$ Because patients with the proximal 1 p36 deletion including case 1 demonstrated different clinical characteristics from cases of typical chromosome 1p36 deletion syndrome, in the near term their clinical features should be redefined as an independent syndrome. ${ }^{46}$

CNVs containing pathogenic gene(s). In four cases we identified pCNVs that contained a gene(s) probably responsible for phenotypes. In case 10 , the CNV had a deletion harboring GLI3 (OMIM: ${ }^{*} 165240$ )
Table 2 Other cases among 54 positive cases in the first screening

\begin{tabular}{|c|c|c|c|c|}
\hline \multirow[b]{2}{*}{ Gender } & \multicolumn{2}{|c|}{ Position where CNV detected } & \multirow[b]{2}{*}{ Corresponding disorder } & \multirow[b]{2}{*}{ OMIM } \\
\hline & Gain & Loss & & \\
\hline \multirow[t]{2}{*}{$\mathrm{F}$} & & $4 p 16.3$ & Ring chromosome & \\
\hline & & $4 q 35.2$ & & \\
\hline M & & $3 q 22.323$ & BPES & \#110100 \\
\hline M & & $2 q 22.3$ & ZFHX1B region & *605802 \\
\hline M & & $4 q 22.1$ & Synuclein (SNCA) region & *163890 \\
\hline $\mathrm{F}$ & & $7 p 21.1$ & Craniosynostosis, type 1 & \#123100 \\
\hline $\mathrm{F}$ & & $7 q 11.23$ & Williams syndrome & \#194050 \\
\hline $\mathrm{F}$ & & $8 q 23.3 q 24.11$ & Langer-Giedion syndrome & \#150230 \\
\hline M & $15 q 11.2 q 13.1$ & & Prader-Willi/Angelman & $\begin{array}{l}\# 176270 / \\
\# 105830\end{array}$ \\
\hline $\mathrm{F}$ & & $17 p 11.2$ & Smith-Magenis syndrome & \#182290 \\
\hline M & & $17 q 11.2$ & Neurofibromatosis, type I & +162200 \\
\hline M & $22 q 11.21$ & & DiGeorge syndrome & \#188400 \\
\hline $\mathrm{F}$ & & $22 q 11.21$ & DiGeorge syndrome & \#188400 \\
\hline $\mathrm{F}$ & Xp22.31 & & Kallmann syndrome 1 & +308700 \\
\hline $\mathrm{F}$ & Whole X & & Mosaicism & \\
\hline
\end{tabular}

Abbreviations: CNV, copy-number variant; F, female; M, male; OMIM, Online Mendelian Inheritance in Man.

accounting for Greig cephalopolysyndactyly syndrome (GCS; OMIM: 175700). ${ }^{47}$ Although phenotypes of the patient, for example, pre-axial polydactyly of the hands and feet, were consistent with GCS, his severe and atypical features of GCS, for example, MR or microcephaly, might be affected by other contiguous genes contained in the deletion. ${ }^{48}$ Heterozygous deletions of BMP4 (OMIM: $\left.{ }^{\star} 112262\right)$ in case 11 and CASK (OMIM: ${ }^{\star} 300172$ ) in case 13 have been reported previously. ${ }^{49,50}$ In case 12 , the $\mathrm{CNV}$ contained YWHAE (OMIM: $\left.{ }^{\star} 605066\right)$ whose haploinsufficiency would be involved in MR and mild CNS dysmorphology of the patient because a previous report demonstrated that haploinsufficiency of $y$ whae caused a defect of neuronal migration in mice ${ }^{51}$ and a recent report also described a microdeletion of YWHAE in a patient with brain malformation..$^{52}$

Recurrent CNVs in the same regions. We also considered recurrent CNVs in the same region as pathogenic; three pairs of patients had overlapping CNVs, which have never been reported previously. Case 16 had a 3.3-Mb heterozygous deletion at 10q24.31-q25.1 and case 17 had a $2.0-\mathrm{Mb}$ deletion at 10q24.32-q25.1. The clinical and genetic information will be reported elsewhere. Likewise, cases 14 and 15 also had an overlapping CNV at 6q12-q14.1 and 6q14.1, and cases 18 and 19 had an overlapping CNV at 10p12.1-p11.23. Hereafter, more additional cases with the recurrent $\mathrm{CNV}$ would assist in defining new syndromes.

CNVs reported as pathogenic in previous studies. Five cases were applicable to these criteria. A deletion at 3p21.2 in case 20 overlapped with that in one case recently reported. ${ }^{53}$ The following four cases had CNVs reported as pathogenic in recent studies: a CNV at 7 p22.1 in case 21 overlapped with that of patient 6545 in a study by Friedman et al. ${ }^{14}$ a CNV at 14q11.2 in case 22 overlapped with those of patients 8326 and 5566 in Friedman et al., ${ }^{14}$ a CNV at 17q24.1-q24.2 in case 23 overlapped with that in patient 99 in Buysse et al. ${ }^{54}$ and a $\mathrm{CNV}$ at 19 p13.2 in case 24 overlapped with case P11 in Fan et al. ${ }^{55}$

Large or gene-rich CNVs, or CNVs containing morbid OMIM genes. In cases inapplicable to the above criteria, we assessed CNVs 


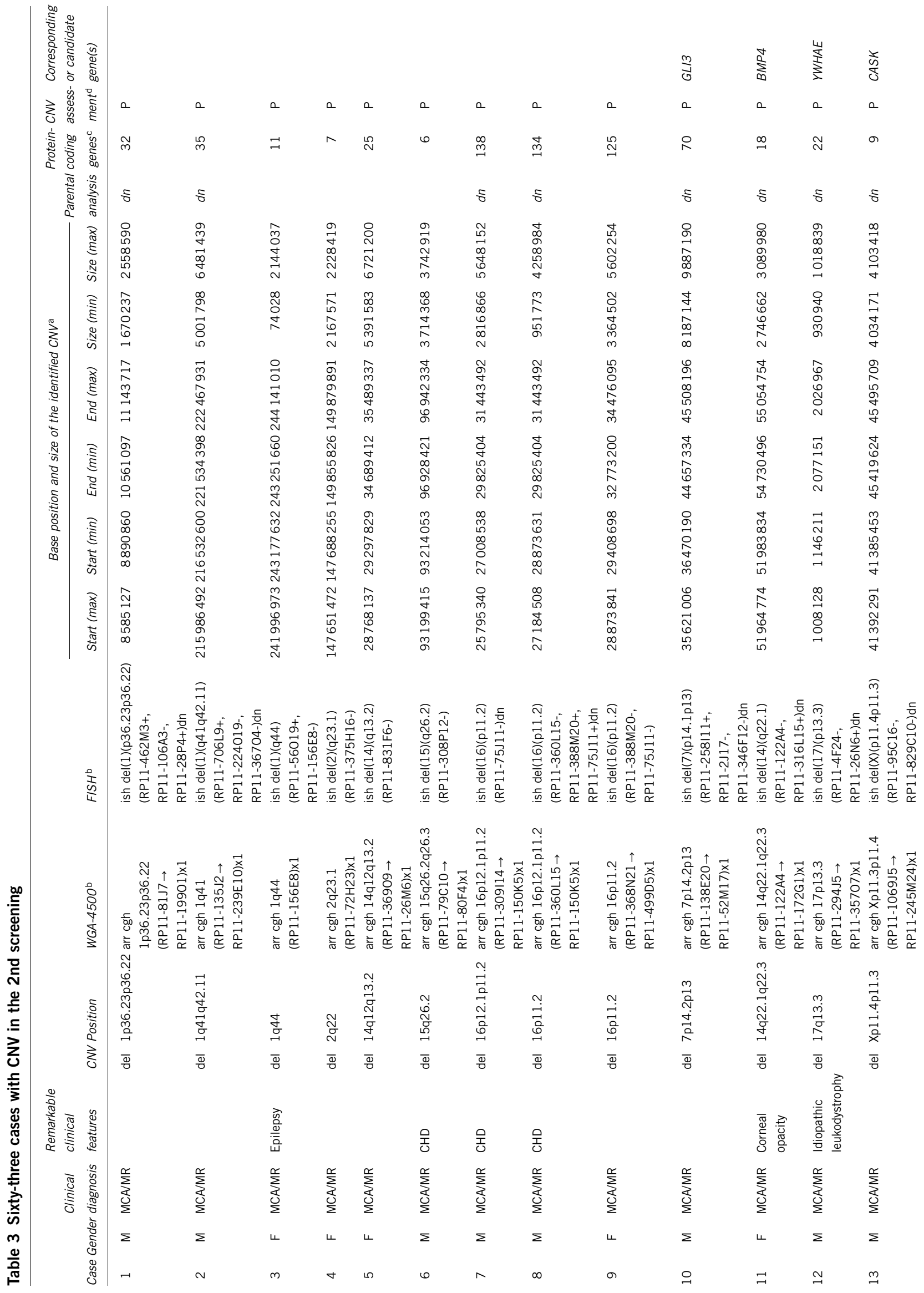




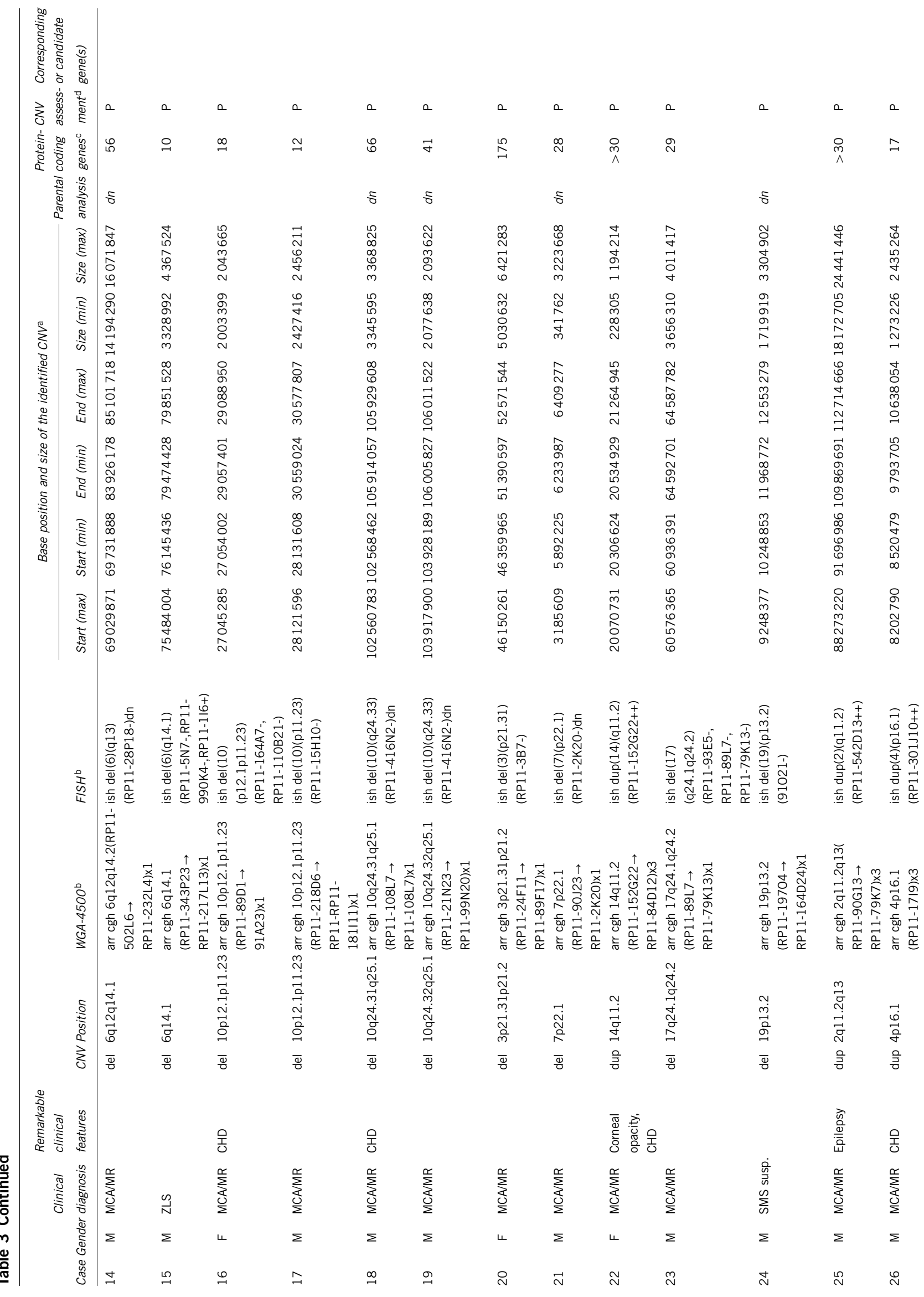









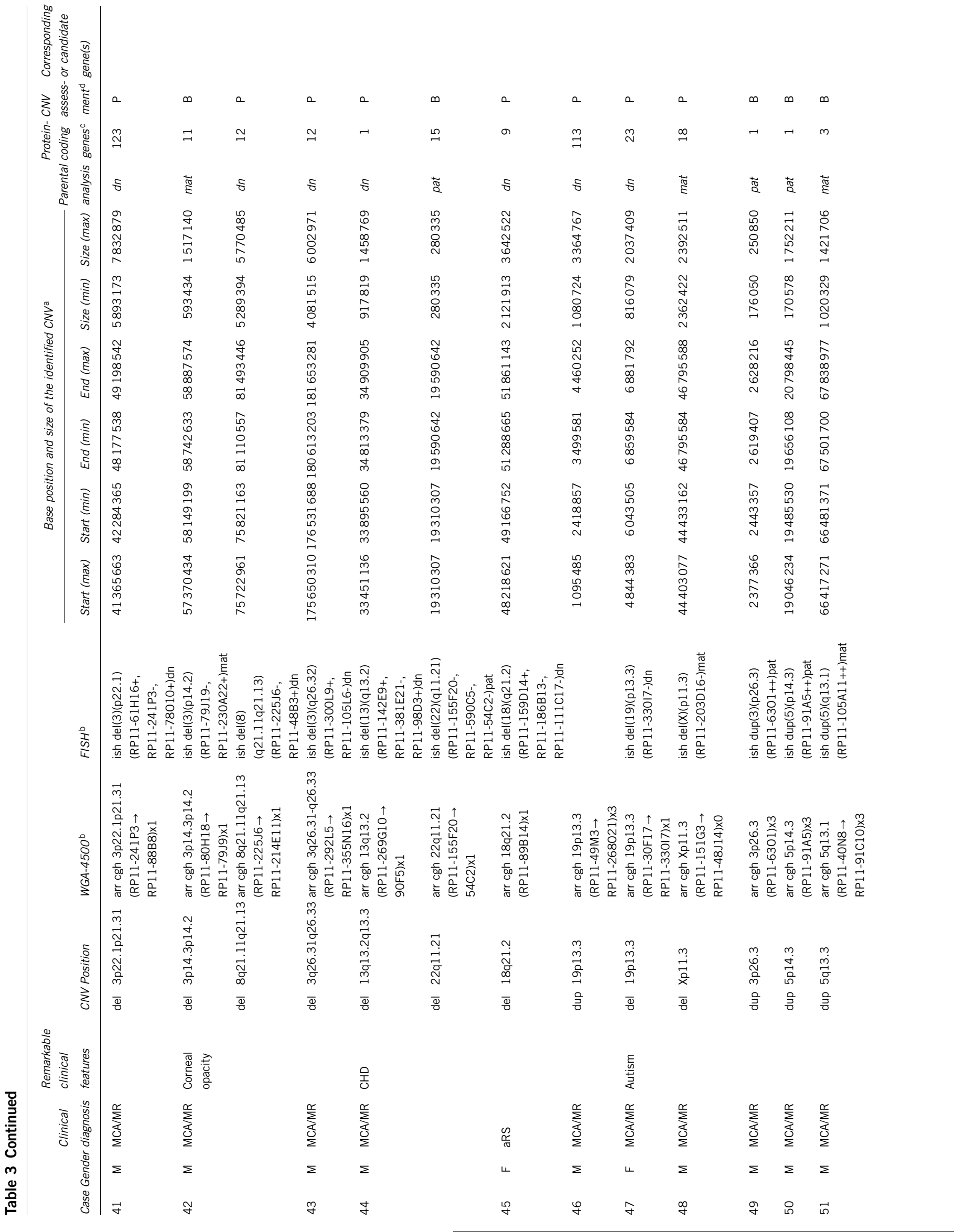




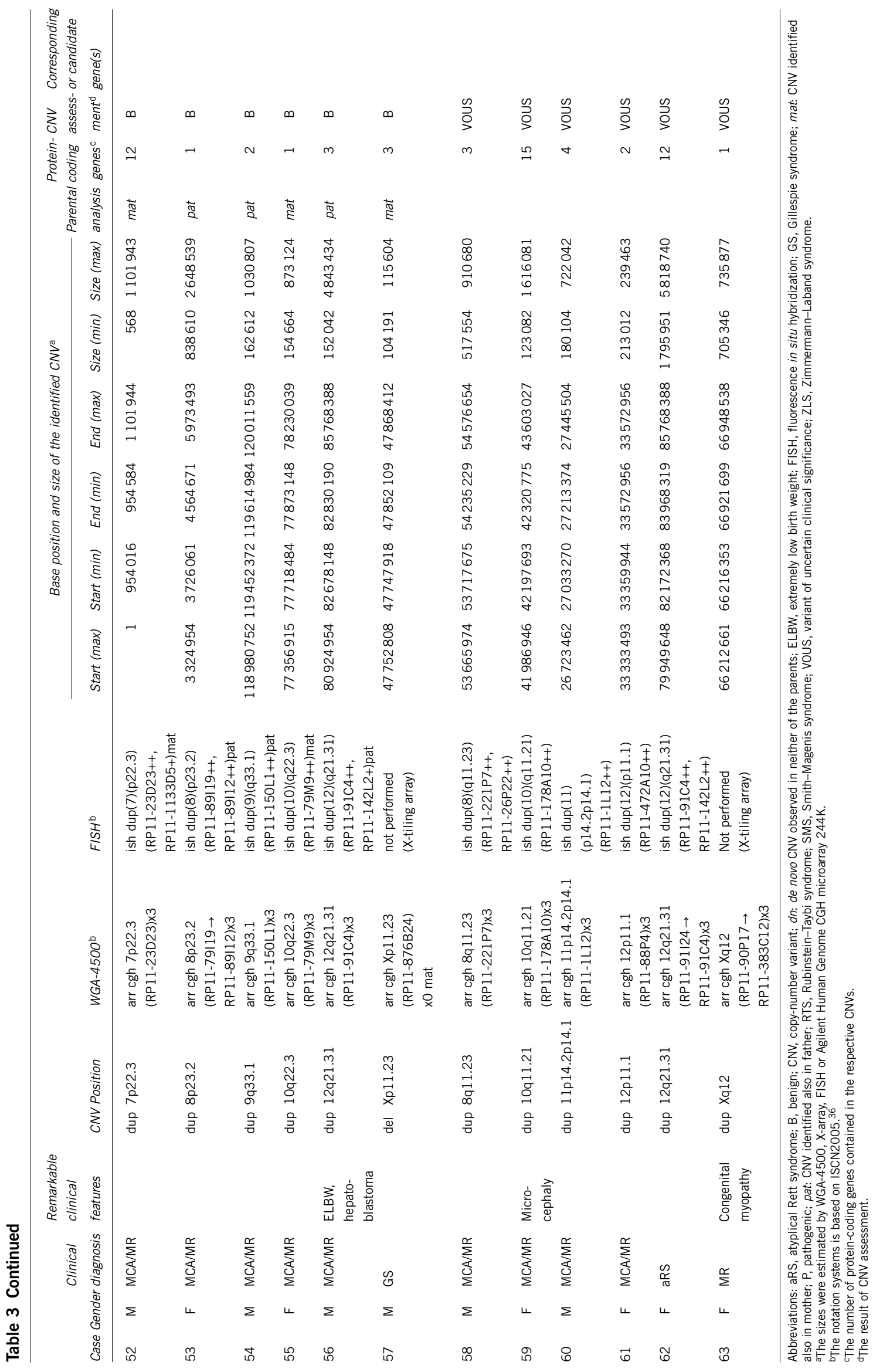




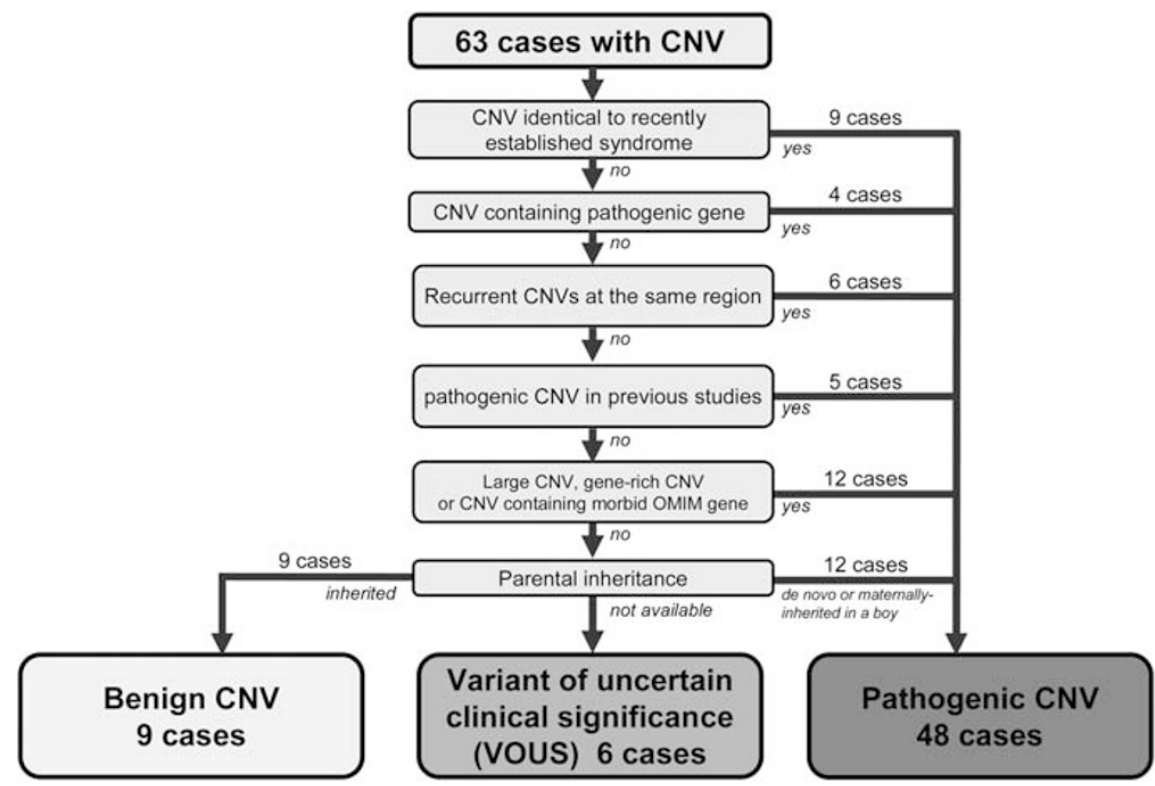

Figure $2 \mathrm{~A}$ flowchart of the assessment of CNVs detected in the second screening.

from several aspects. A CNV that contains abundant genes or is large ( $>3 \mathrm{Mb}$ ) has a high possibility to be pathogenic. ${ }^{21}$ The CNVs in cases 25-30 probably correspond to such CNVs. Also, we judged a CNV containing a morbid OMIM gene as pathogenic:21 TBR1 (OMIM: ${ }^{\star} 604616$ ) in case $31,{ }^{56}$ SUMF1 (OMIM: ${ }^{\star} 607939$ ) in case $32,57,58$ SEMA3A (OMIM: ${ }^{\star} 603961$ ) in case $33,{ }^{59}$ EML1 (OMIM: ${ }^{\star} 602033$ ) and/or YY1 (OMIM: ${ }^{\star} 600013$ ) in case $34,{ }^{60,61}$ A2BP1 (OMIM: $\left.{ }^{\star} 605104\right)$ in case $35^{62}$ and IL1RAPL1 (OMIM: $\left.{ }^{*} 300206\right)$ in case $36{ }^{63}$ Several previous reports suggest that these genes are likely to be pathogenic, although at present no evidence of a direct association between these genes and phenotypes exists.

CNVs de novo or $X$ maternally inherited. Among the remaining 27 cases, 12 cases had CNVs considered pathogenic as their CNVs were de novo (cases 37-47) or inherited $\operatorname{del}(\mathrm{X})(\mathrm{p} 11.3)$ from the mother (case 48). In the second screening we performed FISH for $36 \mathrm{CNVs}$ of the 34 cases whose parental samples were available to confirm that 24 cases had de novo CNVs, which were probably pathogenic. A CNV in case 48 , a boy with a nullizygous deletion at Xp11.3 inherited from his mother, was also probably relevant to his phenotype (Tables 3 and 4). Meanwhile, although case 57 was a boy with a deletion at Xp11.23 inherited from his mother, he was clinically diagnosed with Gillespie syndrome (OMIM: \#206700) that was reported to show an autosomal dominant or recessive pattern, ${ }^{64}$ thus we judged that the deletion was not relevant to his phenotype. As a result, cases $49-57$ had only CNVs inherited from one of their parents which are likely to be unrelated to the phenotypes; that is, bCNV (Table 4).

As a result, we estimated that 48 cases among 349 analyzed (13.8\%) had $\mathrm{pCNV}(\mathrm{s})$ in the second screening (Table 3; Figure 2). The CNVs of the remaining six cases, cases 58-63, were not associated with previously reported pathogenicity and their inheritance could not be evaluated, thus we estimated they were variants of uncertain clinical significance (VOUS). ${ }^{38}$

\section{DISCUSSION}

Because aCGH is a high-throughput technique to detect CNVs rapidly and comprehensively, this technique has been commonly used for analyses of patients with MCA and/or MR. ${ }^{38,65-68}$ However, recent studies of human genomic variation have uncovered surprising properties of CNV, which covers $3.5-12 \%$ of the human genome even in healthy populations. ${ }^{18-20,69}$ Thus analyses of patients with uncertain clinical phenotypes need to assess whether the $\mathrm{CNV}$ is pathogenic or unrelated to phenotypes. ${ }^{21}$ However, such an assessment may diminish the rapidness or convenience of aCGH.

In this study, we evaluated whether our in-house GDA can work well as a diagnostic tool to detect CNVs responsible for wellestablished syndromes or those involved in subtelomeric aberrations in a clinical setting, and then explored candidate pCNVs in cases without any CNV in the first GDA screening. We recruited 536 cases that had been undiagnosed clinically and studied them in a two-stage screening using aCGH. In the first screening we detected CNVs in 54 cases $(10.1 \%)$. Among them, 40 cases had $\mathrm{CNV}(\mathrm{s})$ at subtelomeric region(s) corresponding to the well-established syndromes or the already described disorders and the other 14 cases had CNVs in the regions corresponding to known disorders. Thus about three quarters of cases had genomic aberrations involved in subtelomeric regions. All the subtelomeric deletions and a part of the subtelomeric duplications corresponded to the disorders, indicating that especially subtelomeric deletions had more clinical significance compared to subtelomeric duplications, although the duplication might result in milder phenotypes and/or function as a modifier of phenotypes. ${ }^{70}$ Moreover, parental analysis in three cases with two subtelomeric aberrations revealed that two of them were derived from the parental balanced translocations, indicating that such subtelomeric aberrations were potentially recurrent and parental analyses were worth performing. Recently several similar studies analyzed patients with MCA/MR or developmental delay using a targeted array for subtelomeric regions and/or known genomic disorders and detected clinically relevant CNVs in $4.4-17.1 \%$ of the patients. ${ }^{28,65,70,71}$ Our detection rate in the first screening was equivalent to these reports. Although such detection rates depend on the type of microarray, patient selection criteria and/or number of subjects, these results suggest that at least $10 \%$ of cases with undiagnosed MCA/MR and a normal karyotype would be detectable by targeted array. 
Table 4 Parental analysis of 34 cases in the second screening

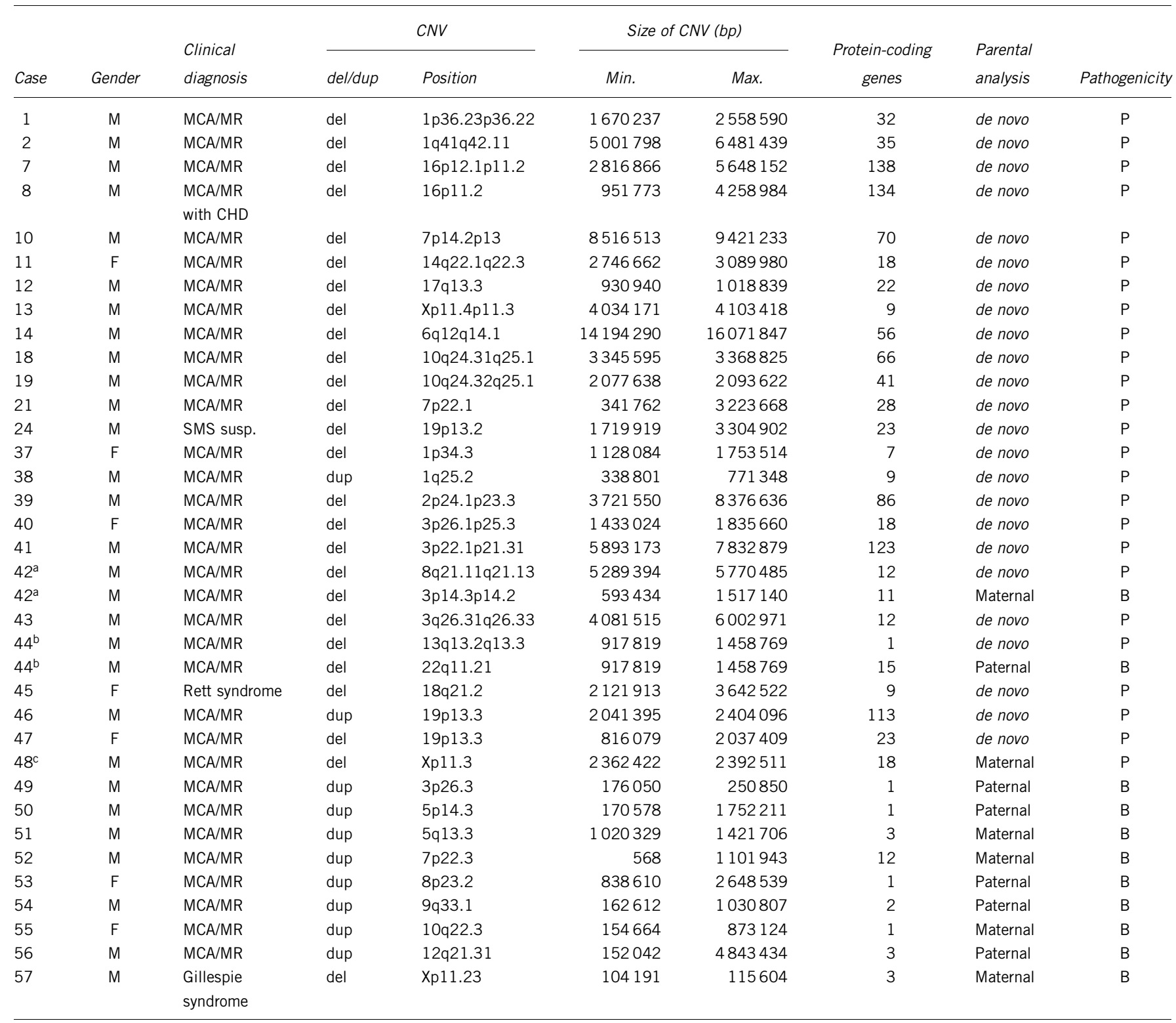

Abbreviations: B, benign; CNV, copy-number variant; F, female; M, male; MCA/MR, multiple congenital anomalies and mental retardation; P, pathogenic. aTwo CNVs were detected in case 42.

Two CNVs were detected in cas

${ }^{\mathrm{c} N u l l i z y g o u s}$ deletion inherited from his mother probably affected the phenotype.

Another interesting observation in the first screening was that subtelomeric rearrangements frequently occurred even in patients with MCA/MR of uncertain whose karyotype had been diagnosed as normal. This result may be consistent with a property of subtelomeric regions whose rearrangements can be missed in conventional karyotyping, ${ }^{72}$ and in fact other techniques involving subtelomeric FISH or MLPA also identified subtelomeric abnormalities in a number of patients with MCA and/or MR in previous reports. ${ }^{70,73,74}$ Our result may support the availability of prompt screening of subtelomeric regions for cases with uncertain congenital disorders.

In the second screening we applied WGA-4500 to 349 cases to detect 66 candidate pCNVs in 63 cases $(18.1 \%)$, and subsequently assessed the pathogenicity of these CNVs. The pCNVs included nine
CNVs overlapping identical regions of recently recognized syndromes (cases 1-9; deletion at 1p36.23-p36.22, 1q41-q42.11, 1q43-q44, 2q23.1, 14q12, 15q26-qter and 16p11.2-p12.2, respectively), four CNVs containing disease-associated genes (cases 10-13; GLI3, BMP4, YWHAE and CASK, respectively), three pairs of CNVs of recurrent deletions (cases 14, 15: at 6q12-q14.1 and 6q14.1; case 16, 17: at 10p12.1-p11.23 and case 18, 19: at 10q24.31-q25.1 and 10q24.32-q25.1), five CNVs identical to pCNVs in previous studies (cases 20-24), six large and/or gene-rich CNVs (cases 25-30) and six CNVs containing a morbid OMIM gene (cases 31-36). For the remaining cases, we estimated the pathogenicity of the CNVs from a parental analysis (Table 4). We judged the 11 de novo CNVs (cases 37-47) and $1 \mathrm{CNV}$ on chromosome Xp11.3 inherited from 
the mother (case 48) as probably pathogenic. And nine inherited CNVs (cases 49-57) were probably benign. The clinical significance of CNVs in the other six cases, cases 58-63, remains uncertain (VOUS). As a result we estimated CNVs as pathogenic in 48 cases among 349 cases $(13.8 \%)$ analyzed in the second screening. None of the pCNVs corresponded to loci of well-established syndromes. This may suggest that our two-stage screening achieved a good balance between rapid screening of known syndromes and investigation of $\mathrm{CNV}$ of uncertain pathogenicity.

Table 5 Summary of parental analyses

\begin{tabular}{|c|c|c|c|c|}
\hline & & \multicolumn{2}{|c|}{ Average size (bp) } & \multirow{2}{*}{$\begin{array}{c}\text { The average number of } \\
\text { protein-coding genes }\end{array}$} \\
\hline & & Min. & Max. & \\
\hline \multicolumn{5}{|c|}{ Pathogenic CNVs } \\
\hline del & 23 & 3309267 & 4597689 & 43 \\
\hline dup & 2 & 1190098 & 1587722 & 61 \\
\hline Total & 25 & 3139733 & 4356892 & 44 \\
\hline \multicolumn{5}{|c|}{ Benign $C N V s^{b}$} \\
\hline del & 3 & 538481 & 1030504 & 10 \\
\hline dup & 8 & 334432 & 1740327 & 3 \\
\hline Total & 11 & 390082 & 1546739 & 5 \\
\hline
\end{tabular}

Abbreviation: CNV, copy-number variant.

Twenty-four de novo CNVs and case 48.

bEleven inherited CNVs other than case 48 .
Among the cases with parental analyses, the 25 pCNVs had larger sizes and contained more protein-coding genes (average size, $3.1 \mathrm{Mb}$ at minimum to $4.4 \mathrm{Mb}$ at maximum; average number of genes, 44) as compared with the 11 inherited bCNVs that were probably unrelated to phenotypes (average size, $0.39 \mathrm{Mb}$ at minimum to $1.5 \mathrm{Mb}$ at maximum; average number of genes, 5) (Table 5). Although all of the 25 pCNVs except 2 were deletions, about three quarters ( 8 of 11 cases) of the inherited bCNVs were duplications (Table 5). These findings are consistent with previously reported features of pCNVs and bCNVs. ${ }^{21,38}$

We also compared our current study with recent aCGH studies meeting the following conditions: (1) a microarray targeted to whole genome was applied; (2) patients with MCA and/or MR of uncertain etiology, normal karyotype and the criteria for patients selection were clearly described; (3) pathogenicity of identified CNVs were assessed. On the basis of the above criteria, among studies reported in the past 5 years, we summarized 13 studies (Table 6). ${ }^{10,14,15,17,54,55,75-81}$ Diagnostic yield of pCNVs in each study was $6.3-16.4 \%$, and our current diagnostic yield of the second screening was $13.8 \%$. Though cases with subtelomeric aberration detected in the first screening had been excluded, our diagnostic yield was comparable to those of the reported studies. It is not so important to make a simple comparison between diagnostic yields in different studies as they would depend on the conditions of each study, for example, sample size or array resolution, ${ }^{38,82}$ however it seems interesting that the higher resolution of a microarray does not ensure an increase in the rate of detection of pCNVs. One recent study showed data that may explain the discrepancy between the resolution of microarray and diagnostic yield. ${ }^{54,83}$ The authors analyzed 1001 patients with MCA and/or MR using one

Table 6 Previous studies of analyzing patients with MCA and/or MR using aCGH targeted to whole genome

\begin{tabular}{|c|c|c|c|c|c|c|c|}
\hline \multirow[b]{2}{*}{ Author (year) } & \multicolumn{3}{|c|}{ Applied array } & \multicolumn{2}{|c|}{ Patients } & \multicolumn{2}{|c|}{ Pathogenic CNV } \\
\hline & Type & Number ${ }^{\mathrm{a}}$ & Distribution $^{\mathrm{b}}$ & Number & Type of disorders & Number & $\%$ \\
\hline Schoumans et al. ${ }^{75}$ & $\mathrm{BAC}$ & 2600 & $1.0 \mathrm{Mb}^{*}$ & 41 & MCA and MR & 4 & 9.8 \\
\hline de Vries et al. ${ }^{76}$ & $\mathrm{BAC}$ & 32477 & Tiling & 100 & MCA and/or MR & 10 & 10.0 \\
\hline Rosenberg et al. ${ }^{77}$ & BAC & 3500 & $1.0 \mathrm{Mb}^{*}$ & 81 & MCA and MR & 13 & 16.0 \\
\hline Krepischi-Santos et al. ${ }^{78}$ & BAC & 3500 & $1.0 \mathrm{Mb}^{*}$ & 95 & MCA and/or MR & 15 & 15.8 \\
\hline Friedman et al. ${ }^{14}$ & SNP & Affymetrix 100K & $23.6 \mathrm{~kb}^{* *}$ & 100 & MR & 11 & 11.0 \\
\hline Thuresson et al. ${ }^{79}$ & $\mathrm{BAC}$ & & $1.0 \mathrm{Mb}^{*}$ & 48 & MCA and MR & 3 & 6.3 \\
\hline Wagenstaller et al. ${ }^{80}$ & SNP & Affymetrix $100 \mathrm{~K}$ & $23.6 \mathrm{~kb}^{* *}$ & 67 & MR & 11 & 16.4 \\
\hline Fan et al. ${ }^{55}$ & Oligo & Agilent $44 \mathrm{~K}$ & $24 \mathrm{~kb}-43 \mathrm{~kb} * *$ & $100^{c}$ & MCA and MR, Autism & $15^{d}$ & 15.0 \\
\hline Xiang et al. ${ }^{15}$ & Oligo & Agilent $44 \mathrm{~K}$ & $24 k b-43 k b^{* *}$ & $40^{e}$ & MR, DD and autism & 3 & 7.5 \\
\hline Pickering et al. ${ }^{10}$ & $\mathrm{BAC}$ & 2600 & $1 \mathrm{Mb}^{*}$ & $354^{f}$ & MCA and/or MR & $36^{g}$ & 10.2 \\
\hline McMullan et al. ${ }^{17}$ & SNP & Affymetrix 500K & $2.5 \mathrm{~kb}-5.8 \mathrm{~kb} \mathrm{~b}^{* *}$ & 120 & MCA and/or MR & 18 & 15.0 \\
\hline Bruno et al. ${ }^{81}$ & SNP & Affymetrix $250 \mathrm{~K}$ & $2.5 \mathrm{~kb}-5.8 \mathrm{~kb}$ ** & 117 & MCA and/or MR & 18 & 15.4 \\
\hline \multirow[t]{2}{*}{ Buysse et al. ${ }^{54}$} & $\mathrm{BAC}$ & 3431 & $1 \mathrm{Mb}^{*}$ & 298 & MCA and/or MR & 26 & 8.7 \\
\hline & Oligo & Agilent 44K & $24 k b-43 k b^{* *}$ & 703 & MCA and/or MR & 74 & 10.5 \\
\hline Our current study & $\mathrm{BAC}$ & 4523 & $0.7 \mathrm{Mb}$ & 349 & MCA and MR & 48 & 13.8 \\
\hline \multicolumn{4}{|l|}{ Total } & 2613 & & 305 & 11.7 \\
\hline \multicolumn{8}{|c|}{$\begin{array}{l}\text { Abbreviations: BAC, bacterial artificial chromosome; CNV, copy-number variant; DD, developmental delay; MCA, multiple congenita } \\
\text { polymorphism. } \\
\text { aThe number of clones or name of array is described. } \\
\text { bEach distribution referred to each article }\left(^{*}\right) \text { or manual of each manufacturer }\left(^{* *}\right) \text {. } \\
\text { cAll cases were analyzed by both a targeted array and a genome-wide array. } \\
\text { IIn five cases, CNVs were also identified by a targeted array. } \\
\text { eTen cases with an abnormal karyotype were excluded. } \\
\text { fOnly cases studied with an array throughout the genome are described. Ninety-eight cases were also analyzed by a targeted array. } \\
\text { gSeventeen cases with an abnormal karyotype were excluded. }\end{array}$} \\
\hline
\end{tabular}


of two types of microarray, BAC array and oligonucleotide array. The BAC array was applied for 298 patients to detect 58 CNVs in 47 patients, and among them $26 \mathrm{CNVs}(8.7 \%)$ were determined to be causal (pathogenic). Conversely, the oligonucleotide arrays were applied for 703 patients to detect $1538 \mathrm{CNVs}$ in 603 patients, and among them $74 \mathrm{CNVs}(10.5 \%)$ were determined to be pathogenic. These results may lead to the following idea: a lower-resolution microarray detects a limited number of CNVs likely to be pathogenic, because such CNVs tend to be large, and a higher-resolution microarray detects an increasing number of bCNVs or VOUS. ${ }^{38}$ Indeed, in studies using a high-resolution microarray, most of the CNVs detected were smaller than $500 \mathrm{~kb}$ but almost all pCNVs were relatively large. ${ }^{54,81,83}$ Most of the small CNVs were judged not to be pathogenic, and the percentage of pCNVs stabilized at around $10 \%$. This percentage may suggest a frequency of patients with MCA/MR caused by $\mathrm{CNV}$ affecting one or more genes, other than known syndromes and subtelomeric aberrations. The other patients may be affected by another cause undetectable by genomic microarray; for example a point mutation or microdeletion/duplication of a single gene, aberration of microRNA, aberration of methylation states, epigenetic aberration or partial uniparental disomy.

As recently hypothesized secondary insult, which is potentially another CNV, a mutation in a phenotypically related gene or an environmental event influencing the phenotype, may result in clinical manifestation. ${ }^{84}$ Especially, in two-hit CNVs, two models have been hypothesized: (1) the additive model of two co-occurring CNVs affecting independent functional modules and (2) the epistatic model of two CNVs affecting the same functional module. ${ }^{85}$ It also suggests difficulty in selecting an optimal platform in the clinical screening. Nevertheless, information on both pCNVs and bCNVs detected through studies using several types of microarrays is unambiguously significant because an accumulation of the CNVs will create a map of genotype-phenotype correlation that would determine the clinical significance of each CNV, illuminate gene function or establish a new syndrome.

\section{ACKNOWLEDGEMENTS}

We thank Ayako Takahashi and Rumi Mori for technical assistance. This study was supported by the Joint Usage/Research Program of Medical Research Institute, Tokyo Medical and Dental University. This work was also supported by grants-in-aid for Scientific Research on Priority Areas from the Ministry of Education, Culture, Sports, Science, and Technology, Japan; a grant from Core Research for Evolutional Science and Technology (CREST) of the Japan Science and Technology Corporation (JST); a grant from the New Energy and Industrial Technology Development Organization (NEDO); and in part by Grant-in-Aid for Scientific Research (B) $(17390099,20390301)$ of Japan Society for the Promotion of Science (JSPS); Health and Labour Sciences Research Grants for Research on information system of undiagnosed diseases (H21nanchi-ippan-167) and Research on policy for intractable diseases (H22nanchi-shitei-001) from the Ministry of Health, Labour and Welfare, Japan.

1 Roeleveld, N., Zielhuis, G. A. \& Gabreëls, F. The prevalence of mental retardation: a critical review of recent literature. Dev. Med. Child Neurol. 39, 125-132 (1997).

2 Hunter, A. G. Outcome of the routine assessment of patients with mental retardation in a genetics clinic. Am. J. Med. Genet. 90, 60-68 (2000)

3 Smith, D. W. \& Bostian, K. E. Congenital anomalies associated with idiopathic mental retardation. J. Pediatr. 65, 189-196 (1964).

4 Gustavson, K. H., Hagberg, B., Hagberg, G. \& Sars, K. Severe mental retardation in a Swedish county. II. Etiologic and pathogenetic aspects of children born 1959-1970. Neuropadiatrie 8, 293-304 (1977).

5 Fryns, J. P., Kleczkowska, A., Kubieñ, E. \& Van den Berghe, H. Cytogenetic findings in moderate and severe mental retardation. A study of an institutionalized population of 1991 patients. Acta. Paediatr. Scand. Suppl. 313, 1-23 (1984).
6 Gustavson, K. H., Holmgren, G. \& Blomquist, H. K. Chromosomal aberrations in mildly mentally retarded children in a northern Swedish county. Ups. J. Med. Sci. Suppl. 44, 165-168 (1987).

7 Schreppers-Tijdink, G. A., Curfs, L. M., Wiegers, A., Kleczkowska, A. \& Fryns, J. P. A systematic cytogenetic study of a population of 1170 mentally retarded and/or behaviourly disturbed patients including fragile X-screening. The Hondsberg experience. J. Genet Hum. 36, 425-446 (1988).

8 van Karnebeek, C. D., Koevoets, C., Sluijter, S., Bijlsma, E. K., Smeets, D. F., Redeker, E. J. et al. Prospective screening for subtelomeric rearrangements in children with mental retardation of unknown aetiology: the Amsterdam experience. J. Med. Genet. 39, 546-553 (2002).

9 Vissers, L. E., de Vries, B. B., Osoegawa, K., Janssen, I. M., Feuth, T., Choy, C. O. et al. Array-based comparative genomic hybridization for the genomewide detection of submicroscopic chromosomal abnormalities. Am. J. Hum. Genet. 73, 1261-1270 (2003).

10 Pickering, D. L., Eudy, J. D., Olney, A. H., Dave, B. J., Golden, D., Stevens, J. et al. Array-based comparative genomic hybridization analysis of 1176 consecutive clinical genetics investigations. Genet. Med. 10, 262-266 (2008).

11 Bauters, M., Van Esch, H., Marynen, P. \& Froyen, G. X chromosome array-CGH for the identification of novel X-linked mental retardation genes. Eur. J. Med. Genet. 48, 263-275 (2005).

12 Hayashi, S., Honda, S., Minaguchi, M., Makita, Y., Okamoto, N., Kosaki, R. et al. Construction of a high-density and high-resolution human chromosome $\mathrm{X}$ array for comparative genomic hybridization analysis. J. Hum. Genet. 52, 397-405 (2007).

13 Kok, K., Dijkhuizen, T., Swart, Y. E., Zorgdrager, H., van der Vlies, P., Fehrmann, R. et al. Application of a comprehensive subtelomere array in clinical diagnosis of mental retardation. Eur. J. Med. Genet. 48, 250-262 (2005).

14 Friedman, J. M., Baross, A., Delaney, A. D., Ally, A., Arbour, L., Armstrong, L. et al. Oligonucleotide microarray analysis of genomic imbalance in children with mental retardation. Am. J. Hum. Genet. 79, 500-513 (2006).

15 Xiang, B., Li, A., Valentin, D., Nowak, N. J., Zhao, H. \& Li, P. Analytical and clinical validity of whole-genome oligonucleotide array comparative genomic hybridization for pediatric patients with mental retardation and developmental delay. Am. J. Med. Genet. 146A, 1942-1954 (2008).

16 Shen, Y., Irons, M., Miller, D. T., Cheung, S. W., Lip, V., Sheng, X. et al. Development of a focused oligonucleotide-array comparative genomic hybridization chip for clinical diagnosis of genomic imbalance. Clin. Chem. 53, 2051-2059 (2007).

17 McMullan, D. J., Bonin, M., Hehir-Kwa, J. Y., de Vries, B. B., Dufke, A., Rattenberry, E. et al. Molecular karyotyping of patients with unexplained mental retardation by SNP arrays: a multicenter study. Hum. Mutat. 30, 1082-1092 (2009).

18 lafrate, A. J., Feuk, L., Rivera, M. N., Listewnik, M. L., Donahoe, P. K., Qi, Y. et al. Detection of large-scale variation in the human genome. Nat. Genet. 36, 949-951 (2004).

19 Sebat, J., Lakshmi, B., Troge, J., Alexander, J., Young, J., Lundin, P. et al. Large-scale copy number polymorphism in the human genome. Science. 305, 525-528 (2004).

20 Redon, R., Ishikawa, S., Fitch, K. R., Feuk, L., Perry, G. H., Andrews, T. D. et al. Global variation in copy number in the human genome. Nature 444, 444-454 (2006).

21 Lee, C., lafrate, A. J. \& Brothman, A. R. Copy number variations and clinical cytogenetic diagnosis of constitutional disorders. Nat. Genet. 39, S48-S54 (2007).

22 Inazawa, J., Inoue, J. \& Imoto, I. Comparative genomic hybridization (CGH)-arrays pave the way for identification of novel cancer-related genes. Cancer Sci. 95, 559-563 (2004).

23 Hayashi, S., Kurosawa, K., Imoto, I., Mizutani, S. \& Inazawa, J. Detection of cryptic chromosome aberrations in a patient with a balanced $t(1 ; 9)(\mathrm{p} 34.2 ; \mathrm{p} 24)$ by array-based comparative genomic hybridization. Am. J. Med. Genet. 139, 32-36 (2005).

24 Shrimpton, A. E., Braddock, B. R., Thomson, L. L., Stein, C. K. \& Hoo, J. J. Molecular delineation of deletions on 2 q37.3 in three cases with an Albright hereditary osteodystrophy-like phenotype. Clin. Genet. 66, 537-544 (2004).

25 Rauch, A. \& Dörr, H. G. Chromosome 5q subtelomeric deletion syndrome. Am. J. Med. Genet. C 145C, 372-376 (2007).

26 Horn, D., Tönnies, H., Neitzel, H., Wahl, D., Hinkel, G. K., von Moers, A. et al. Minimal clinical expression of the holoprosencephaly spectrum and of Currarino syndrome due to different cytogenetic rearrangements deleting the Sonic Hedgehog gene and the HLXB9 gene at 7q36.3. Am. J. Med. Genet. A 128A, 85-92 (2004).

27 Tatton-Brown, K., Pilz, D. T., Orstavik, K. H., Patton, M., Barber, J. C., Collinson, M. N. et al. $15 q$ overgrowth syndrome: a newly recognized phenotype associated with overgrowth, learning difficulties, characteristic facial appearance, renal anomalies and increased dosage of distal chromosome 15q. Am. J. Med. Genet. A 149A, 147-154 (2009).

28 Lu, X., Shaw, C. A., Patel, A., Li, J., Cooper, M. L., Wells, W. R. et al. Clinical implementation of chromosomal microarray analysis: summary of 2513 postnatal cases. PLoS One 2, e327 (2007).

29 Fernandez, T. V., García-González, I. J., Mason, C. E., Hernández-Zaragoza, G., Ledezma-Rodríguez, V. C., Anguiano-Alvarez, V. M. et al. Molecular characterization of a patient with $3 p$ deletion syndrome and a review of the literature. Am. J. Med. Genet. A 146A, 2746-2752 (2008).

30 Jones, K. L. Smith's Recognizable Patterns of Human Malformation, 6th edn. (Elsevier Saunders, Philadelphia, 2006).

31 Striano, P., Malacarne, M., Cavani, S., Pierluigi, M., Rinaldi, R., Cavaliere, M. L. et al. Clinical phenotype and molecular characterization of $6 \mathrm{q}$ terminal deletion syndrome: five new cases. Am. J. Med. Genet. A 140, 1944-1949 (2006). 
32 Lindstrand, A., Malmgren, H., Verri, A., Benetti, E., Eriksson, M., Nordgren, A. et al. Molecular and clinical characterization of patients with overlapping 10p deletions. Am. J. Med. Genet. A 152A, 1233-1243 (2010).

33 Elbracht, M., Roos, A., Schönherr, N., Busse, S., Damen, R., Zerres, K. et al. Pure distal trisomy $2 \mathrm{q}$ : a rare chromosomal abnormality with recognizable phenotype. Am. J. Med. Genet. A 149A, 2547-2550 (2009).

34 Lukusa, T. \& Fryns, J. P. Pure de novo 17q25.3 micro duplication characterized by micro array CGH in a dysmorphic infant with growth retardation, developmental delay and distal arthrogryposis. Genet. Couns. 21, 25-34 (2010).

35 Fukami, M., Kirsch, S., Schiller, S., Richter, A., Benes, V., Franco, B. et al. A member of a gene family on Xp22.3, VCX-A, is deleted in patients with X-linked nonspecific mental retardation. Am. J. Hum. Genet. 67, 563-573 (2000).

36 Shaffer, L. G. \& Tommerup, N. An International System for Human Cytogenetic Nomenclature (2005) (Karger, Basel, 2005).

37 Koolen, D. A., Pfundt, R., de Leeuw, N., Hehir-Kwa, J. Y., Nillesen, W. M., Neefs, I. et al. Genomic microarrays in mental retardation: a practical workflow for diagnostic applications. Hum. Mutat. 30, 283-292 (2009).

38 Miller, D. T., Adam, M. P., Aradhya, S., Biesecker, L. G., Brothman, A. R., Carter, N. P. et al. Consensus statement: chromosomal microarray is a first-tier clinical diagnostic test for individuals with developmental disabilities or congenital anomalies. Am. J. Hum. Genet. 86, 749-764 (2010).

39 Shaffer, L. G., Theisen, A., Bejiani, B. A., Ballif, B. C., Aylsworth, A. S., Lim, C. et al. The discovery of microdeletion syndromes in the post-genomic era: review of the methodology and characterization of a new $1 \mathrm{q} 41 \mathrm{q} 42$ microdeletion syndrome. Genet. Med. 9, 607-616 (2007).

40 van Bon, B. W., Koolen, D. A., Borgatti, R., Magee, A., Garcia-Minaur, S., Rooms, L. et al. Clinical and molecular characteristics of 1 qter microdeletion syndrome: delineating a critical region for corpus callosum agenesis/hypogenesis. J. Med. Genet. 45, 346354 (2008)

41 van Bon, B. W., Koolen, D. A., Brueton, L., McMullan, D., Lichtenbelt, K. D., Adès, L. C. et al. The 2q23.1 microdeletion syndrome: clinical and behavioural phenotype. Eur. J. Hum. Genet. 18, 163-170 (2010).

42 Mencarelli, M. A., Kleefstra, T., Katzaki, E., Papa, F. T., Cohen, M., Pfundt, R. et al. $14 q 12$ microdeletion syndrome and congenital variant of Rett syndrome. Eur. J. Med. Genet. 52, 148-152 (2009).

43 Rump, P., Dijkhuizen, T., Sikkema-Raddatz, B., Lemmink, H. H., Vos, Y. J., Verheij, J. B. et al. Drayer's syndrome of mental retardation, microcephaly, short stature and absent phalanges is caused by a recurrent deletion of chromosome 15(q26.2 $\rightarrow$ qter). Clin. Genet. 74, 455-462 (2008).

44 Ballif, B. C., Hornor, S. A., Jenkins, E., Madan-Khetarpal, S., Surti, U., Jackson, K. E. et al. Discovery of a previously unrecognized microdeletion syndrome of $16 \mathrm{p} 11.2$ p12.2. Nat. Genet. 39, 1071-1073 (2007).

45 Shinawi, M., Liu, P., Kang, S. H., Shen, J., Belmont, J. W., Scott, D. A. et al. Recurrent reciprocal $16 \mathrm{p} 11.2$ rearrangements associated with global developmental delay, behavioral problems, dysmorphism, epilepsy, and abnormal head size. J. Med. Genet 47, 332-341 (2010).

46 Kang, S. H., Scheffer, A., Ou, Z., Li, J., Scaglia, F., Belmont, J. et al. Identification of proximal 1 p36 deletions using array-CGH: a possible new syndrome. Clin. Genet. 72, 329-338 (2007).

47 Johnston, J. J., Olivos-Glander, I., Killoran, C., Elson, E., Turner, J. T., Peters, K. F. et al. Molecular and clinical analyses of Greig cephalopolysyndactyly and Pallister-Hall syndromes: robust phenotype prediction from the type and position of GLI3 mutations. Am. J. Hum. Genet. 76, 609-622 (2005).

48 Johnston, J. J., Olivos-Glander, I., Turner, J., Aleck, K., Bird, L. M., Mehta, L. et al. Clinical and molecular delineation of the Greig cephalopolysyndactyly contiguous gene deletion syndrome and its distinction from acrocallosal syndrome. Am. J. Med. Genet. A 123A, 236-242 (2003).

49 Hayashi, S., Okamoto, N., Makita, Y., Hata, A., Imoto, I. \& Inazawa, J. Heterozygous deletion at 14q22.1-q22.3 including the BMP4 gene in a patient with psychomotor retardation, congenital corneal opacity and feet polysyndactyly. Am. J. Med. Genet. A 146A, 2905-2910 (2008).

50 Hayashi, S., Mizuno, S., Migita, O., Okuyama, T., Makita, Y., Hata, A. et al. The CASK gene harbored in a deletion detected by array-CGH as a potential candidate for a gene causative of X-linked dominant mental retardation. Am. J. Med. Genet. A 146A, 2145 2151 (2008)

51 Toyo-oka, K., Shionoya, A., Gambello, M. J., Cardoso, C., Leventer, R., Ward, H. L. et al. 14-3-3epsilon is important for neuronal migration by binding to NUDEL: a molecular explanation for Miller-Dieker syndrome. Nat. Genet. 34, 274-285 (2003).

52 Mignon-Ravix, C., Cacciagli, P., El-Waly, B., Moncla, A., Milh, M., Girard, N. et al. Deletion of YWHAE in a patient with periventricular heterotopias and marked corpus callosum hypoplasia. J. Med. Genet. 47, 132-136 (2010).

53 Haldeman-Englert, C. R., Gai, X., Perin, J. C., Ciano, M., Halbach, S. S., Geiger, E. A. et al. A 3.1-Mb microdeletion of 3p21.31 associated with cortical blindness, cleft lip, CNS abnormalities, and developmental delay. Eur. J. Med. Genet. 52, 265-268 (2009).

54 Buysse, K., Delle Chiaie, B., Van Coster, R., Loeys, B., De Paepe, A., Mortier, G. et al. Challenges for CNV interpretation in clinical molecular karyotyping: lessons learned from a 1001 sample experience. Eur. J. Med. Genet. 52, 398-403 (2009).

55 Fan, Y. S., Jayakar, P., Zhu, H., Barbouth, D., Sacharow, S., Morales, A. et al. Detection of pathogenic gene copy number variations in patients with mental retardation by genomewide oligonucleotide array comparative genomic hybridization. Hum. Mutat. 28, 1124-1132 (2007).

56 Hevner, R. F., Shi, L., Justice, N., Hsueh, Y., Sheng, M., Smiga, S. et al. Tbr 1 regulates differentiation of the preplate and layer 6. Neuron 29, 353-366 (2001).

57 Cosma, M. P., Pepe, S., Annunziata, I., Newbold, R. F., Grompe, M., Parenti, G. et al. The multiple sulfatase deficiency gene encodes an essential and limiting factor for the activity of sulfatases. Cell 113, 445-456 (2003).

58 Dierks, T., Schmidt, B., Borissenko, L. V., Peng, J., Preusser, A., Mariappan, M. et al. Multiple sulfatase deficiency is caused by mutations in the gene encoding the human C(alpha)-formylglycine generating enzyme. Cell 113, 435-444 (2003).

59 Behar, O., Golden, J. A., Mashimo, H., Schoen, F. J. \& Fishman, M. C. Semaphorin III is needed for normal patterning and growth of nerves, bones and heart. Nature 383, 525-528 (1996).

60 Eudy, J. D., Ma-Edmonds, M., Yao, S. F., Talmadge, C. B., Kelley, P. M., Weston, M. D. et al. Isolation of a novel human homologue of the gene coding for echinoderm microtubule-associated protein (EMAP) from the Usher syndrome type 1a locus at 14q32. Genomics 43, 104-106 (1997).

$61 \mathrm{He}, \mathrm{Y}$. \& Casaccia-Bonnefil, P. The Yin and Yang of YY1 in the nervous system. J. Neurochem. 106, 1493-1502 (2008).

62 Martin, C. L., Duvall, J. A., Ilkin, Y., Simon, J. S., Arreaza, M. G., Wilkes, K. et al. Cytogenetic and molecular characterization of A2BP1/FOX1 as a candidate gene for autism. Am. J. Med. Genet. 144B, 869-876 (2007).

63 Tabolacci, E., Pomponi, M. G., Pietrobono, R., Terracciano, A., Chiurazzi, P. \& Neri, G. A truncating mutation in the IL1RAPL1 gene is responsible for X-linked mental retardation in the MRX21 family. Am. J. Med. Genet. 140, 482-487 (2006).

64 Nelson, J., Flaherty, M. \& Grattan-Smith, P. Gillespie syndrome: a report of two further cases. Am. J. Med. Genet. 71, 134-138 (1997).

65 Shaffer, L. G. \& Bejjani, B. A. Medical applications of array CGH and the transformation of clinical cytogenetics. Cytogenet. Genome Res. 115, 303-309 (2006).

66 Shaffer, L. G., Bejjani, B. A., Torchia, B., Kirkpatrick, S., Coppinger, J. \& Ballif, B. C. The identification of microdeletion syndromes and other chromosome abnormalities: cytogenetic methods of the past, new technologies for the future. Am. J. Med. Genet. C Semin. Med. Genet. 145C, 335-345 (2007).

67 Bejjani, B. A. \& Shaffer, L. G. Clinical utility of contemporary molecular cytogenetics. Annu. Rev. Genomics Hum. Genet. 9, 71-86 (2008).

68 Edelmann, L. \& Hirschhorn, K. Clinical utility of array CGH for the detection of chromosomal imbalances associated with mental retardation and multiple congenital anomalies. Ann. NY Acad. Sci. 1151, 157-166 (2009).

69 de Ståhl, T. D., Sandgren, J., Piotrowski, A., Nord, H., Andersson, R., Menzel, U. et al. Profiling of copy number variations (CNVs) in healthy individuals from three ethnic groups using a human genome 32K BAC-clone-based array. Hum. Mutat. 29, 398-408 (2008).

70 Shao, L., Shaw, C. A., Lu, X. Y., Sahoo, T., Bacino, C. A., Lalani, S. R. et al. Identification of chromosome abnormalities in subtelomeric regions by microarray analysis: a study of 5,380 cases. Am. J. Med. Genet. A 146A, 2242-2251 (2008)

71 Lu, X., Phung, M. T., Shaw, C. A., Pham, K., Neil, S. E., Patel, A. et al. Genomic imbalances in neonates with birth defects: high detection rates by using chromosomal microarray analysis. Pediatrics 122, 1310-1318 (2008).

$72 \mathrm{Xu}, \mathrm{J}$. \& Chen, Z. Advances in molecular cytogenetics for the evaluation of mental retardation. Am. J. Med. Genet C Semin. Med. Genet. 117C, 15-24 (2003).

73 Ravnan, J. B., Tepperberg, J. H., Papenhausen, P., Lamb, A. N., Hedrick, J., Eash, D. et al. Subtelomere FISH analysis of 11688 cases: an evaluation of the frequency and pattern of subtelomere rearrangements in individuals with developmental disabilities. J. Med. Genet. 43, 478-489 (2006).

74 Ahn, J. W., Ogilvie, C. M., Welch, A., Thomas, H., Madula, R., Hills, A. et al. Detection of subtelomere imbalance using MLPA: validation, development of an analysis protocol, and application in a diagnostic centre. BMC Med. Genet. 8, 9 (2007).

75 Schoumans, J., Ruivenkamp, C., Holmberg, E., Kyllerman, M., Anderlid, B. M. \& Nordenskjold, M. Detection of chromosomal imbalances in children with idiopathic mental retardation by array based comparative genomic hybridisation (array-CGH). J. Med. Genet. 42, 699-705 (2005).

76 de Vries, B. B., Pfundt, R., Leisink, M., Koolen, D. A., Vissers, L. E., Janssen, I. M. et al. Diagnostic genome profiling in mental retardation. Am. J. Hum. Genet. 77, 606-616 (2005).

77 Rosenberg, C., Knijnenburg, J., Bakker, E., Vianna-Morgante, A. M., Sloos, W., Otto, P. A. et al. Array-CGH detection of micro rearrangements in mentally retarded individuals: clinical significance of imbalances present both in affected children and normal parents. J. Med. Genet. 43, 180-186 (2006)

78 Krepischi-Santos, A. C., Vianna-Morgante, A. M., Jehee, F. S., Passos-Bueno, M. R., Knijnenburg, J., Szuhai, K. et al. Whole-genome array-CGH screening in undiagnosed syndromic patients: old syndromes revisited and new alterations. Cytogenet. Genome Res. 115, 254-261 (2006).

79 Thuresson, A. C., Bondeson, M. L., Edeby, C., Ellis, P., Langford, C., Dumanski, J. P. et al. Whole-genome array-CGH for detection of submicroscopic chromosomal imbalances in children with mental retardation. Cytogenet. Genome Res. 118, 1-7 (2007).

80 Wagenstaller, J., Spranger, S., Lorenz-Depiereux, B., Kazmierczak, B., Nathrath, M., Wahl, D. et al. Copy-number variations measured by single-nucleotide-polymorphism oligonucleotide arrays in patients with mental retardation. Am. J. Hum. Genet. 81, 768-779 (2007). 
81 Bruno, D. L., Ganesamoorthy, D., Schoumans, J., Bankier, A., Coman, D., Delatycki, M. et al. Detection of cryptic pathogenic copy number variations and constitutional loss of heterozygosity using high resolution SNP microarray analysis in 117 patients referred for cytogenetic analysis and impact on clinical practice. J. Med. Genet. 46, 123-131 (2009).

82 Sagoo, G. S., Butterworth, A. S., Sanderson, S., Shaw-Smith, C., Higgins, J. P. \& Burton, H. Array CGH in patients with learning disability (mental retardation) and congenital anomalies: updated systematic review and meta-analysis of 19 studies and 13,926 subjects. Genet. Med. 11, 139-146 (2009).
83 Wincent, J., Anderlid, B. M., Lagerberg, M., Nordenskjöld, M. \& Schoumans, J. High-resolution molecular karyotyping in patients with developmental delay and/or multiple congenital anomalies in a clinical setting. Clin. Genet. (e-pub ahead of print 8 May 2010).

84 Girirajan, S., Rosenfeld, J. A., Cooper, G. M., Antonacci, F., Siswara, P., Itsara, A. et al. A recurrent $16 \mathrm{p} 12.1$ microdeletion supports model for severe developmental delay. Nat. Genet. 42, 203-209 (2010).

85 Veltman, J. A. \& Brunner, H. G. Understanding variable expressivity in microdeletion syndromes. Nat. Genet. 42, 192-193 (2010). 